\title{
Health problems and health care seeking behavior of street children in Dhaka city
}

\begin{abstract}
This cross sectional study was conducted among 150 conveniently selected street children in different area of Dhaka city. Face to face interview was done through semi structured questionnaire. Data analysis was done with Statistical package for social science (SPSS). The study was carried out at Kamalapur railway station, Sadarghat launch terminal, Shishu Park, Chandrema uddan and Ramna Park during the period of January- March 2017.Out of 150 street children majority (66.7\%) were male and 33.3 $\%$ were female. Majority ( $84 \%$ ) of respondents informed that they used public toilet and $76 \%$ performed open air defecation. Majority $(83.3 \%)$ of the respondents had a history of illness in the last 3 months. Majority of the respondent suffered from fever then dysentery, skin problems, and accidents. Health seeking behavior of the street children shows majority (68.1\%) received treatment from medicine shop, $12.9 \%$ from faith-healer, $33.6 \%$ homeopathy, $11.2 \%$ from kabiraj, $28.4 \%$ from hospital, very few (8.6\%) from MBBS doctor, $3.4 \%$ private clinic and $4.3 \%$ from others sources. Street children are the most marginalized, neglected part of society with very negligible access to health care and lack of awareness on available health services.
\end{abstract}

Volume 5 Issue | - 2018

Ishrat Rafique Eshita

Hyperbaric Medicine, Public Health, Bangladesh

Correspondence: Ishrat Rafique Eshita, Hyperbaric Medicine, Public Health, Bangladesh, Email ishrateshita@gmail.com

Received: December 28, 2017 | Published: February 08, 2018

Keywords: health problems, health care seeking behavior

\section{Introduction}

The most common definition of a street child or youth is "any girl or boy who has not reached adulthood, for whom the street has become her or his habitual abode and/or sources of livelihood, and who is inadequately protected, supervised or directed by responsible adults" (Inter-NGO, 1985). UNICEF defines street children as, "those who are of the street and on the street." "Children of the street" are homeless children who live and sleep on the streets in urban areas. They are totally on their own, living with other street children or homeless adult street people. On the other hand, "children on the street" earn their living or beg for money on the street and return home at night. They are extremely vulnerable to sexually transmitted diseases including HIV/AIDS. An estimated $90 \%$ of them are addicted to inhalants such as shoe glue and paint thinner, which cause kidney failure, irreversible brain damage and, in some cases, death. UNICEF estimated 100million children were growing up on urban streets around the world. 14years later UNICEF reported: 'The latest estimates put the numbers of these children as high as 100million' (UNICEF, 2002). It is likely that the numbers are increasing' (UNICEF, 2005). The 100million figures are still commonly cited, but have no basis in fact. Similarly, it is debatable whether numbers of street children are growing globally or whether it is the awareness of street children within societies which has grown. ${ }^{1}$

In Bangladesh, as in many developing countries, there is a widespread belief amongst the public, policymakers and social workers that children 'abandon' their families and migrate to the street because of economic poverty. In Bangladesh, those who seek to reduce the flow of children to the streets need to focus on social policy, especially on how to reduce the excessive control and emotional, physical and sexual violence that occurs in some households. Economic growth and reductions in income poverty will be helpful, but they will not be sufficient to reduce street migration by children. Street children are extremely vulnerable to sexually transmitted diseases, including HIV/AIDS. ${ }^{2}$ Up to 90 percent of street children use psychoactive substances, including medicines, alcohol, cigarettes, heroin, cannabis, and readily available industrial products such as shoe or cobblers' glue and paint thinner. The potent fumes of these cheap and easily available inhalants hit a part of the child's brain that suppresses feelings of hunger, cold, and loneliness. They suffer from some physical and psychological problems-hallucinations, pulmonary edema (fluid accumulation and swelling in the lungs), kidney failure, irreversible brain damage and, in some cases, sudden death. The place of their abode is the street, railway stations, bridges, beneath fly over, temples and digraphs. They grow up on the margins of the society without love, care, protection and supervision of adults. Street children are deprived of their basic rights of survival, protection, development and participation. ${ }^{3}$ Civic amenities like latrines and bathing facilities are beyond their reach. Due to constant exposure to the unhealthy conditions of living on the streets, children suffer from a range of ailments. Lack of an access to basic services of shelter, health care, education and training, lack or alternative livelihood options, lack of societal acceptance and legal status (for want of ration cards) are the major issues of street children. The problem of street children is multifaceted and needs to be understood in proper perspective. Professional social work intervention strategies are necessary to address their needs and problems. ${ }^{4}$

Street children's lives revolve around survival. They tackle health problems by finding their own strategies to overcome or cope with them. Often, street children neglector treat illnesses on their own for as long as they can. This behavior often aggravates their health problems. ${ }^{5}$ Street children often attempt self-medication, such as applying 'masala' (spices) or 'chuna' (quicklime) towounds, drinking 'soda' for gastro-intestinal problems, and taking over-the-counter drugs for all kinds of infections. In addition, recourse to addictive substances is seen as an alternative to dealing with all kinds of physical, mental and emotional health problems. Health care seeking by street children is usually restricted by a number of factors, including the availability 
of resources, knowledge of health centers; time spent seeking care, travel distance, and faith in the health provider (clinics and doctors') ${ }^{6}$ A number of street children like other children, fear doctors and hospitals. Most street children are also unable to access public health services due to improper behavior of hospital staff. Street children and NGOs also report that doctors refuse to treat or operate needy street children because of their unclean appearance. Often public hospitals expect street children to pay user fees and purchase medicines from private medical shops. As a result many of them do not complete their treatment. ${ }^{7}$ GOs working with street children appear to provide easy access. Around more than a third of the children get health services from NGOs, and a fifth of the children reported that the NGO officials take care of them during their illness. However when asked organizational assistance almost all $(96.67 \%)$ said that they did not get any assistance from any governmental organization that work with street children and are thus unaware of their role and existence. ${ }^{8}$

A study was conducted among street children of Dhaka City. The general objective of the study was to know the socio-economic and demographic background of street children and to examine/ assess the street children vulnerability to STD/HIV/AIDS. Total 350 Street children aged between 5-14years were purposively selected. Exploitation, harassment and abuse include sexual abuse were the major problem of the street children. The street children usually do not visit the clinic/hospital or doctor for health care during the episodes of their illness for poverty and ignorance. There are also addicted to injectable drugs and to other substances. Though less, it was found that the street children are also habituated to professional blood donation. Among them awareness of STD/HIV/AIDS is very poor. Another study was conducted in Pakistan to elicit street children's perceptions of health and the barriers to service utilization. A descriptive, crosssectional study was carried out during September and October 2000. They found that these youth were highly susceptible to many adverse health outcomes. The common ailments were injuries, respiratory and skin infections. Along with low self-perceived severity of medical problems, self-medication was preferred and medical pluralism existed. Their perceived constraints to services included long waiting time, monetary, negative attitude of service providers and their inferior status. In developing user-friendly services, it is important to be sensitive to street children's needs and requirements. Eliminating these barriers and the integration of health services among public and private resources are imperative for the regular and sustainable provision of health care to this vulnerable, under-served group of children. ${ }^{9}$

\section{Materials and methods}

This cross sectional study was conducted among 150 purposively selected street children at Kamalapur railway station, Sadarghat launch terminal, Shishu Park, Chandrema uddan, Ramna Park in Dhaka city. The study period was January-March 2017. Data were collected by face to face interview using a semi structured questionnaire regarding socio-demographic status, life style, health problems and health care seeking behavior. Data analysis was carried out with the help of SPSS (Statistical package for social science). ${ }^{10}$

\section{Result}

Majority of the respondents $(51.3 \%)$ were in the age group between $10-15$ years $12 \%$ of the street children's age were below 10 years and rest of the street children were that is $36.7 \%$ had 15years or above (Figure 1). Out of 150 street children majority (66.7\%) were male and $33.3 \%$ were female (Figure 2). Over half of the street children that is $54 \%$ were illiterate, followed by $19.3 \%$ were received nonformal education and rest of the children that is $26.7 \%$ were received formal education. Majority that is $94.7 \%$ of the street children were Muslim and 5.3\% children were Hindu (Table 1). Majority that is $126(84 \%)$ of the street children's mother were alive while $83(55.3 \%)$ fathers were alive. On the other hand $16 \%$ that is 24 mothers \& $44.7 \%$ that is 67 fathers were dead. About $16.6 \%$ of the street children had 1-2 siblings, $41.4 \%$ had 3-4 siblings, and $29.4 \%$ had 5-6 and rest of the children that is $12.6 \%$ had $7-8$ siblings. Twenty percent $(20 \%)$ of the street children were beggar, $36.7 \%$ were shopkeeper, $19.3 \%$ were day laborer and $24.7 \%$ were involved in other odd jobs. $25 \%$ of the street children told that gap was due to their parents died, $41.7 \%$ informed that they lived in countryside, $8.3 \%$ told that due to disliked by the parents they had no relationship with them, another $8.3 \%$ told that they dislike their parents so they are away from their parents. Some $16.7 \%$ did not mention any specific reasons of not maintaining relationship with their parents (Table 1). Table 2 shows that about $17 \%$ of the street children used to sleep $4-5$ hours, while $65.3 \%$ like to sleep $6-7$ hours and only $18 \%$ of the street children used to sleep 8 -9hours at night. Over two-third of the street children that is $64.7 \%$ wash clothes and have bath at footpath tube well, $20 \%$ use lake water, $41.3 \%$ of the children use hotel tube-well water and $19.3 \%$ other source of water .approximately $39 \%$ of the street children informed that they use water rarely. About $8.7 \%$ of the street children's drinking water source was tube well water, $63.3 \%$ from supply water from foot path, $73.3 \%$ of the children consume water from hotel and $10.7 \%$ from different sources. Use of toilet by the street children majority that is $84 \%$ informed that they used to public toilet and $76 \%$ performed open air defecation. Only $2.7 \%$ of the street children had a history of taking drugs regularly, $16.7 \%$ were sometimes and rest of the $80.7 \%$ never taken any drug. Around $14.7 \%$ of the street children used to smoke regularly and $25.3 \%$ were occasionally (Figure 3 ).

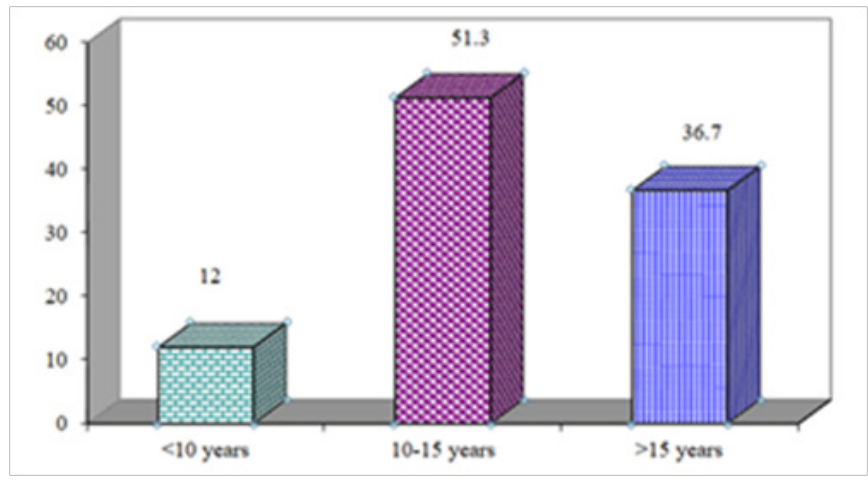

Figure I Age distributions of the street children.

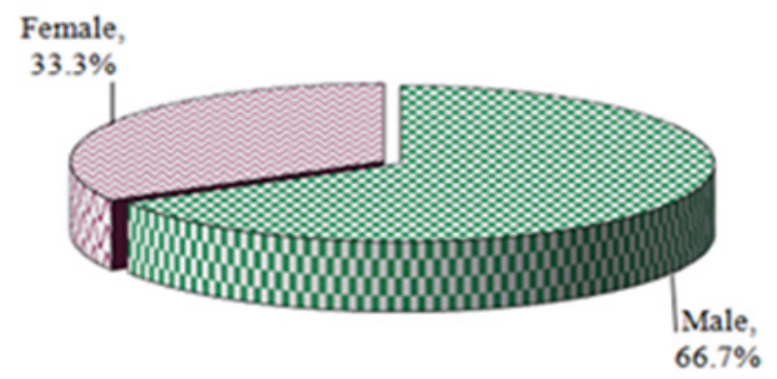

Figure 2 Distribution of the street children by sex. 
Table I Socio demographic characteristics of the street children

\begin{tabular}{|c|c|c|}
\hline Category & Frequency & Percentage \\
\hline \multicolumn{3}{|l|}{ Education } \\
\hline Illiterates & 81 & 54 \\
\hline Non formal & 29 & 19.3 \\
\hline Formal & 40 & 26.7 \\
\hline \multicolumn{3}{|l|}{ Religion } \\
\hline Muslin & 142 & 94.7 \\
\hline Hindu & 8 & 5.3 \\
\hline \multicolumn{3}{|l|}{ Occupation } \\
\hline Beggar & 29 & 19.3 \\
\hline Shopkeeper & 55 & 36.7 \\
\hline Day labor & 29 & 19.3 \\
\hline Others & 37 & 24.7 \\
\hline
\end{tabular}

\section{Parent's Status}

Father

$\begin{array}{lcc}\text { Alive } & 83 & 55.3 \\ \text { Dead } & 67 & 44.7 \\ \text { Mother } & & \\ \text { Alive } & 126 & 84 \\ \text { Dead } & 24 & 16\end{array}$

\section{Number of Siblings}

\begin{tabular}{lcc}
\hline 2-Jan & 25 & 16.6 \\
4-Mar & 62 & 41.4 \\
6-May & 44 & 29.4 \\
8-Jul & 19 & 12.6 \\
\hline
\end{tabular}

\section{Reason of relation gap with} parents

$\begin{array}{lcc}\text { Not alive } & 15 & 25 \\ \text { Live at village } & 25 & 41.7 \\ \text { Parents dislike } & 5 & 8.3 \\ \text { Respondent dislike } & 5 & 8.3 \\ \text { Others } & 10 & 16.7\end{array}$

Table 2 Variables related to lifestyle

\begin{tabular}{lll}
\hline Category & Frequency & Percentage \\
\hline Duration of sleep & & \\
\hline $4-5 \mathrm{hrs}$. & 25 & 16.7 \\
$6-7 \mathrm{hrs}$. & 98 & 65.3 \\
$8-9 \mathrm{hrs}$. & 27 & 18 \\
\hline
\end{tabular}

Sources of washing water

\begin{tabular}{lcc}
\hline Footpath tube well & 97 & 64.7 \\
Lake & 30 & 20 \\
Hotel & 62 & 41.3 \\
Others & 29 & 19.3 \\
No wash & 58 & 38.7 \\
\hline
\end{tabular}

\begin{tabular}{lcc}
\multicolumn{2}{l}{ Sources of drinking water } & \\
\hline Tube Well & 13 & 8.7 \\
Footpath & 95 & 63.3 \\
Hotel & 110 & 73.3 \\
Others & 16 & 13.7 \\
\hline Toilet using & & \\
\hline Public toilet & 126 & 84 \\
Open defecation & 114 & 76 \\
\hline
\end{tabular}

\section{Drug use}

\begin{tabular}{lcc}
\hline Yes & 4 & 2.7 \\
No & 121 & 80.7 \\
Sometimes & 25 & 16.7 \\
\hline Sexual exposure & & \\
\hline Yes & 60 & 40 \\
No & 90 & 69
\end{tabular}

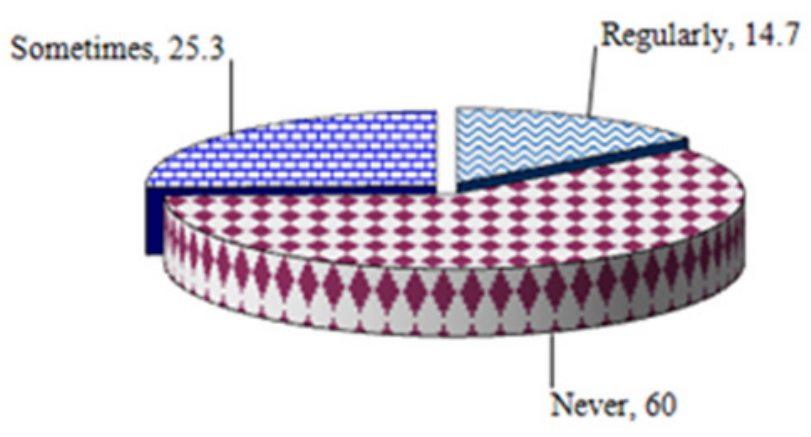

Figure 3 Distribution by street children about smoking practice. 
Table 3 shows that $47.0 \%$ of the street children suffered from RTI, $59.8 \%$ from fever, $50.7 \%$ suffered dysentery, $24.2 \%$ had skin problems, $27.3 \%$ of the street children had different types of accident and rest $21.2 \%$ suffered other different types of health problems. Around $77.3 \%$ of the street children received treatment for illness and $22.7 \%$ were not taken any treatment (Figure 4). Table 4 shows that $54.4 \%$ of the street children were fully cured, $40.4 \%$ were partially cured and rest $5.4 \%$ of the street children were not cured at all and $68.1 \%$ of the street children received treatment from medicine shop, $12.9 \%$ from faith-healer, $33.6 \%$ from homeopathy, $11.2 \%$ from kabiraj, 28.4\% from hospital, $8.6 \%$ from MBBS doctor, $3.4 \%$ private clinic and rest of the $4.3 \%$ of the children from others sources.

Table 3 Health problems suffered by the street children for the last three months

\begin{tabular}{lll}
\hline Type of health problem & Frequency & Percentage \\
\hline Fever & 79 & 59.8 \\
Dysentery & 76 & 50.7 \\
Cough(RTI) & 62 & 47 \\
Accident & 36 & 27.3 \\
Skin problems & 32 & 24.2 \\
Others & 28 & 21.2 \\
\hline
\end{tabular}

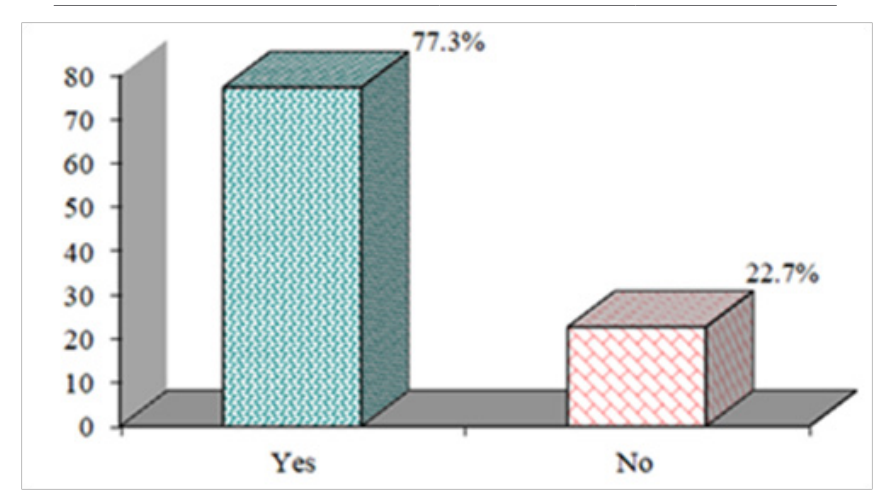

Figure 4 Distribution of the street children by seeking treatment.

Table 4 Distribution of the respondents by health care received and outcome of treatment

\begin{tabular}{lll}
\hline Variables & Frequency & Percentage \\
\hline Sources of health care received & & \\
\hline Medicine Shop & 79 & 68.1 \\
Faith Healer & 15 & 12.9 \\
Homeopathy & 39 & 33.6 \\
Kabiraj & 13 & 11.2 \\
Hospital & 33 & 28.4 \\
MBBS Doctor & 10 & 8.6 \\
Private clinic & 4 & 3.4 \\
Others & 5 & 4.3 \\
\hline
\end{tabular}

Outcome of treatment

\begin{tabular}{lll}
\hline Fully Cured & 62 & 54.4 \\
Partially cured & 46 & 40.4 \\
Not cured & 6 & 5.3 \\
\hline
\end{tabular}

\section{Discussion}

This was a cross sectional study on health status and health care seeking behavior among the street children of Dhaka city. Main objective of the study was to determine the major health problems of the street children, their life style along with treatment seeking behavior. The results revealed that $12 \%$ of the respondents was below 10 years of age, $51.3 \%$ between $10-15$ years and $36.7 \%$ 15years or above. Twothird $(66.7 \%)$ of the respondents was male and majority $(94.7 \%)$ was Muslim. Over half (54\%) was illiterate, $19.3 \%$ non-formal education and $26.7 \%$ formal education. About $20 \%$ of respondents were beggar, $36.7 \%$ shopkeeper, $19.3 \%$ day labourer and $24.7 \%$ involved in other odd jobs. Over $55 \%$ of the respondents' father was alive. About $23 \%$ of respondents' father was unemployed, followed by $21.7 \%$ rickshaw-puller, $18.1 \%$ day labor, $9.6 \%$ beggar, $8.4 \%$ businessman and $19.3 \%$ involved in other diverse occupations. Majority (84\%) of the respondent's mother was alive. Forty percent of the respondents had no relationship with parents. As respondents were asked about the reasons not maintaining any relationship with their parents, $25 \%$ told that they died, $41.7 \%$ informed they lived in countryside, $8.3 \%$ told that their parents disliked them, another $8.3 \%$ told they were disliked by their parents. Some $16.7 \%$ did not mention any specific reasons of not maintaining relationship with their parents. The respondents were primarily hawker $(38.7 \%)$ followed by day-labor $(18 \%)$, beggar (14.7\%), brisk business (11.3\%) and other occupants (17.3\%).

Nearly $30 \%$ of the respondents' working place was park, $24.7 \%$ worked at footpath, $20 \%$ at market, $13.3 \%$ at bus-stand/terminal, $12 \%$ at rail station and rest $1.3 \%$ at other places. About $17 \%$ of the respondents sleep for $4-5$ hours, $65.3 \%$ for $6-7$ hours and $18 \%$ 8-9hours at night. Over two-third (64.7\%) of respondents wash clothes and have bath at footpath tube well, $20 \%$ use lake water, $41.3 \%$ hotel tube-well water and $19.3 \%$ other source of water. Approximately $39 \%$ of the respondents informed that they rarely use water. Asked about source of drinking water, $8.7 \%$ told tube well water, $63.3 \%$ from supply water, $73.3 \%$ from hotel tube-well and $10.7 \%$ from other sources. In response to a question about use of toilet service, majority (84\%) of respondents informed that they used public toilet and $76 \%$ performed open air defecation. In a study conducted in Zimbabwe it was revealed that -thirty-one percent (31.4\%) of the street children had homes to go to at night. Most were staying with at least one biological parent while others were staying with members of the extended family. The $31.4 \%$ of children "on the street" worked on the streets and slept at home. Nearly 12 percent $(11.8 \%)$ were children who slept both on the streets and at their homes. Nearly forty-six percent $(45.7 \%)$ of street children were beggars while $14.7 \%$ were vendors, $21.2 \%$ guarded cars, and $4.1 \%$ were escorting blind parents. The majority $(39.5 \%)$ of the street children had spent one to three years on the street. Street children live in physical surroundings that are unhygienic and dirty. Majority of them do not have access to bathing and toilet facilities. They are constantly exposed to sun, rain, cold, dirt, and smoke, harmful waste and other environmental hazards. Most street children consume food found on the street, in garbage bins, and at cheap roadside stalls. 300 street children were randomly selected and interviewed from 15 places of Dhaka City for a questionnaire survey. Due to limitations of time, money and manpower the selected sample size was small. As the street children come from a similar socio-economic background the findings of the study, although the sample size is small, should have considerable value. Of the 300 street children $84 \%$ were boys and $16 \%$ were girls. The median age for boys was 12 years and girls were 7 to 8years. A majority of the street children (30\%) live with their parents in Dhaka City. Lack of sanitation and hygiene is a major 
health hazard for street children. About half of them bathe in different public places. Use of public toilets was mentioned by a majority of the street children. A significant number of street children use open spaces for toilets and have to pay occasionally for some of these facilities, such as the market toilet.

Majority $(83.3 \%)$ of the respondents had a history of illness in the last 3 months. About $87 \%$ of respondents received treatment for illness. Asked about whether they have had deviant/illicit sexual behavior, forty two percent of the respondents confessed that they had such experiences. Drug history demonstrates that, about $15 \%$ of respondents' smoked regularly and $25.3 \%$ occasionally. A study was conducted among the street children of Dhaka city in 2002 titled "Street Children of Dhaka City: Fever is the most common illness among the street children. The other prevalent illnesses included accident injury, jaundice, chicken pox, allergy, measles, asthma, and diarrhea. About $99 \%$ of the respondents reported that they did fall ill seriously on one or more occasions. The number of street children and women in major towns of Ethiopia is rapidly increasing. In a study was conducted in that country, the study objective was to assess health and related problems in street children and women. Two hundred eighty (55.3\%) of the street children reported one or more previous health problems. Malaria like febrile illnesses $(42.6 \%)$ followed by respiratory tract illnesses $(33.1 \%)$ and diarrheal diseases $(4.5 \%)$ were the major health problems reported. The UNICEF 2005 Report on India had pointed to the fact that about 63 per cent of Indian children go to bed hungry and 53 per cent suffer from chronic malnutrition, Majority of them suffer from protein deficiency and chronic diseases like asthma and dysentery. High prevalence of sexually transmitted diseases among street children makes them highly vulnerable to HIV It is estimated that $60-90 \%$ of street children in Mumbai are sexually active. One of the study done in London on homeless children reported behavioral problems in $49 \%$ of these children. "A higher rate of behavioral problems such as sleep problems, aggression, over activity, shyness, withdrawal and emotional problems such as depression, anxiety, sadness, low self-esteem and self-harm (scratching, head-banging, punching, etc.) was also common. New entrants in the city are generally unaware of the public health services available in different localities. Most street children are also unable to access public health services due to improper behavior of hospital staff. Street children and NGOs also report that doctors refuse to treat or operate needy street children because of their unclean appearance. Fear of rejection and past experiences of unapproachable and unresponsive health providers discourages street children from accessing public health services in times of need. Often public hospitals expect street children to pay user fees and purchase medicines from private medical shops. As a result many of them do not complete their treatment.

\section{Conclusion}

This was a cross sectional study on health status and health care seeking behavior among the street children of Dhaka city. Main objective of the study was to determine the major health problems of the street children, their life style along with treatment seeking behavior. Majority of them were male, from 10-15years of age with no education. Among their occupation begging, shop keeping, laboring were notable with daily income less than $50 \mathrm{Tk}$. Less than half of the respondents had no relationship with parents. In this study according to the statement of the street children there life style was different. Most of them use drinking water from footpath tap or hotel. They use water for wash mainly from lack or footpath tap. They use public toilet but majority of them also use open toilet. They live in an environment which was unhealthy. So, different types of health problems they have to face. Majority of them suffered from fever followed by respiratory treat infection, accident, dysentery, skin infection, all this type of problems are related to their environments and life style. About half of the street children practice smoking, illegal sex, and different types of drug abuse. Ultimately their physical and mental development was hampered. They were brought up an unhealthy, illiterate, and neglected population of the country. Their health care seeking behavior also reflect there economical and liberated mentality. Most of them received treatment from medicine shop, some from traditional heeler, kobiraj, homeopath etc. Very negligible percentage received treatment from MBBS doctor of qualified persons. So the health and life style of the street children surveyed was marked by negligence, poverty, illiteracy and lack of awareness on available health services. They were most marginalized, neglected part of society with very negligible access to health care. The health condition was marked by episode of seasonal and common illnesses and above all malnutrition and hunger.

\section{Acknowledgements}

None.

\section{Conflict of interest}

The author declares no conflict of interest.

\section{References}

1. A Study on Street Children in Zimbabwe. P. 1-16.

2. Street children-What are street children? Mexico.

3. Street children.

4. Conticini A, Hulme D. Escaping Violence, Seeking Freedom: Why Children in Bangladesh Migrate to The Street. PRCPB. 2009;38(2):201227.

5. Canadian International Cooperation Agency (CIDA). Street Children.

6. Hamara Foundation (Mumbai, India). Development Initiative for Street Children.

7. The 'Hospital on Wheels' Project. Making health care accessible to Street children. SNEHA; 2008:1-11.

8. Akter J. Health and living conditions of street children in Dhaka City. Equity Dialogue. 2004:2(4).

9. Nahar N, Ahammed I, Milkey SA. The status of street children of Dhaka Metropolitan area \& their vulnerability to STD/HIV/AIDS. Int Conf AIDS. 2000

10. Ali M, Muynck A. Illness incidence and health seeking behavior among street children in Rawalpindi and Islamabad, Pakistan-a qualitative study. Child Care Health Dev. 2005;31(5):525-532. 